\title{
DIAGNÓSTICO DA DESTINAÇÃO DO SORO DE LEITE NA MESORREGIÃO DO CAMPO DAS VERTENTES - MINAS GERAIS
}

\author{
Diagnosis of thewheydestination in the mesoregion \\ Campo das Vertentes, Minas Gerais, Brazil
}

\author{
Fabiula Ferrarez Silva Gajo ${ }^{1}$, Adriano Alvarenga Gajo², \\ Roberta Bessa Veloso Silva ${ }^{3}$ Eric Batista Ferreira ${ }^{3 *}$
}

\section{RESUMO}

O objetivo deste trabalho foi fazer um diagnóstico dos laticínios da região do Campo das Vertentes no estado de Minas Gerais, quanto à utilização do soro de leite, das perspectivas de mercado e averiguar obstáculos existentes à sua comercialização. O Brasil ocupa, no mundo, a quarta colocação em produção de queijos, sendo que a manufatura de queijos implica a geração de soro. O soro de leite é um subproduto nobre que merece atenção na sua utilização, pois é composto de proteínas, carboidratos, minerais e vitaminas. Para realização do trabalho foram selecionados laticínios produtores de queijo que possuem registro no Serviço de Inspeção Federal (SIF), situados na mesorregião do Campo das Vertentes, no estado de Minas Gerais. A partir da identificação do público alvo, que são os produtores de soro de leite, foi aplicado um questionário semiestruturado, com o objetivo de obter informações. A região do Campo das Vertentes é formada, em sua maioria, por laticínios de pequeno e médio porte, e o destino mais comum do soro de leite é para a alimentação animal e doação, devido à falta de interesse das indústrias ou pela falta de estrutura para aproveitar ou comercializar o produto. Concluiu-se que o aproveitamento do soro de leite pelo próprio laticínio ou a sua comercialização para terceiros, certamente é uma alternativa que, além de levar em consideração a preservação do meio ambiente, agrega valor econômico ao produto final. Pode-se perceber que existem barreiras para que esta prática seja viável.

1 Instituto Federal de Educação, Ciência e Tecnologia Goiano, Goiânia, GO, Brasil.

2 Instituto Federal de Educação, Ciência e Tecnologia do sul de Minas, Pouso Alegre, MG, Brasil.

3 Universidade José do Rosário Vellano/UNIFENAS, Rua Líbano, 66, Bairro Itapoã, 31710-030, Belo Horizonte, MG, Brasil. E-mail: eric.ferreira@unifal-mg.edu.br

* Autor para correspondência. 
Palavras-chave: subproduto; laticínios; produtos lácteos; reaproveitamento; agronegócio.

\begin{abstract}
The objective of this work was to promote a diagnostic of the dairy producers that surrounds the area known as Campo das Vertentes, in Minas Gerais, Brazil. We evaluate the use of whey, the market prospects, and the obstacles to its commercialization. Brazil is the 4th larger producer of cheese in world, which implies in a large whey yield. Whey is a noble byproduct that deserves attention: it is composed by proteins, carbohydrates, minerals and vitamins. Dairy producers registered at Federal Inspection Service (SIF) were selected. It was applied a semi-structured questionnaire to the whey producers. The region of Campo das Vertentes consists mostly of small and medium-sized dairy producers. The most common destination of whey being the animal feed and donation, due to the lack of interest of the industries or lack of structure to take advantage or market the product. It was concluded that the use of whey by the dairy industry itself is certainly an alternative that adds economic value to the final product. Moreover, it takes in consideration the protection of the environment once it is not discarded as wastewater. It can be noted that there are barriers to the use of whey become a feasible practice.
\end{abstract}

Keywords: by product; dairy; milk products; reuse; agribusiness.

\section{INTRODUÇÃO}

De acordo com a Associação Brasileira de Indústrias de Queijos (ABIQ, 2014), o Brasil ocupa no mundo, a quarta colocação em produção de queijos, uma quantidade que gira em torno das 867 mil toneladas/ano.

Segundo Magalhães et al. (2011), há uma preocupação recorrente em gerar aplicação do soro de leite em novos alimentos, visto que no território brasileiro, cerca de $50 \%$ do soro não é aproveitado. Isto gera desperdícios nutricional, financeiro e impactos ambientais relevantes, já que é um resíduo com alto teor orgânico.

Rech (2003) descreve que o soro de leite constitui-se no líquido remanescente após a precipitação e remoção da caseína do leite durante a fabricação de queijo. Este subproduto representa cerca de $80 \%$ a $90 \%$ do volume de leite utilizado e retém $55 \%$ dos nutrientes do leite, sendo em média, $5 \%$ de lactose, proteínas solúveis $0,8 \%$, lipídios $0,5 \%$, sais minerais e $10 \%$ do extrato seco.

Contudo, devido a sua baixa concentração de matéria sólida (7\%), o soro de leite é normalmente considerado um efluente (RECH, 2003).

Uma inovação tecnológica na cadeia de produção agroindustrial do leite, de acordo com Bieger; Rinaldi (2009), é a conversão do soro de leite para insumo, levando-se em consideração a responsabilidade ambiental, que vem ganhando cada vez mais espaço nas indústrias.

Esta alteração gera uma nova fonte de renda para as indústrias mudando o papel do soro de leite de efluente para matéria prima para fabricação de outros produtos.

O aproveitamento do soro pode ser realizado pela utilização do produto líquido na fabricação de outros produtos como ricota e 
bebidas lácteas. Outra alternativa é beneficiar o soro de leite por meio de tratamentotérmico, ultrafiltração, evaporação, entre outras.

Após o beneficiamento, o produto pode ser transformado em soro modificado, concentrado ou em pó. Esta transformação aumenta a vida útil do produto, diminui os custos de transação e viabiliza a comercialização do soro, pois não será necessária a refrigeração, além de diminuir o volume, facilitando a logística de toda a cadeia produtiva.

De acordo com Aliceweb (2015), embora o Brasil produza um volume considerável de soro fluido, o país é caracterizado, historicamente, como um importador de soro em pó.

No ano de 2014 o Brasil exportou 83,47 toneladas de soro de leite e importou $24.036,87$ toneladas, totalizando em um saldo deficitário de $-23.953,40$ toneladas.

Os dados dos últimos dez anos demonstram que o país importou mais que exportou (diferença de $-266.948,12$ toneladas de soro em pó), que em valores monetários, representa o déficit na balança comercial de US\$ FOB -374.068.300,00 (ALICEWEB, 2015).

De acordo com Mizubuti (1994), o soro doce é obtido principalmente pela coagulação enzimática e apresenta pH entre 6,0 e 6,8. A produção da bebida láctea com a utilização do soro doce de leite está ganhando espaço no mercado e se mostra como opção atrativa para utilização na alimentação humana devido à simplicidade do processo e das excelentes propriedades funcionais de suas proteínas (SMITH, 2003).

O soro ácido é formado pela coagulação ácida e apresenta $\mathrm{pH}$ inferior a 6,0. O soro ácido ser utilizado na fabricação de bebidas lácteas fermentadas, no entanto, na maioria dos relatos, existe a necessidade de correção da acidez (RÉVILLION et al., 2000).

Diante disso, o presente trabalho teve como objetivo fazer um diagnóstico nos laticí- nios da mesorregião do Campo das Vertentes, $\mathrm{MG}$, no que se refere a utilização e/ou venda do soro do leite, bem como averiguar as possíveis barreiras existentes à sua comercialização.

\section{MATERIAL E MÉTODOS}

Inicialmente este trabalho foi submetido e aprovado pelo Comitê de Ética em Pesquisa (CEP) da Universidade José do Rosário Vellano/UNIFENAS, sendo o número do parecer: 1.171.024.

A coleta dos dados foi feita por meio da seleção de nove laticínios produtores de queijo que possuem registro no Serviço de Inspeção Federal (SIF). As empresas foram identificadas por meio do banco de dados do Ministério da Agricultura, Pecuária e Abastecimento (MAPA, 2015).

Foi delimitada a área da mesorregião do Campo das Vertentes, no estado de Minas Gerais, sendo formada por três microrregiões: Lavras, Barbacena e São João Del Rei, conforme está apresentado na Figura 1.

A mesorregião do Campo das Vertentes é constituída por 36 municípios, sendo que 12 possuem laticínios com registro do SIF. Esta região foi escolhida devido a concentração de um grande número de laticínios produtores de queijo e pela proximidade a uma empresa multinacional que faz a secagem do soro de leite.

A região do Campo das Vertentes possui 21 fábricas de laticínios cadastradas no Sistema de Inspeção Federal (MAPA, 2015) e as microrregiões que possuem o maior número de estabelecimentos são: a microrregião de São João Del Rei que possui 10 fábricas de laticínios, seguidos de 7 fábricas na microrregião de Lavras e 4 fábricas na microrregião de Barbacena.

Por meio de contato telefônico com os responsáveis pelos laticínios foi feito um convite formal acompanhado de esclarecimento da pesquisa e seus objetivos. 
Um dos pontos ressaltados foi que não haveria a identificação dos participantes. No primeiro momento, buscou-se identificar quais produtos são fabricados para distinguir os estabelecimentos que produziam queijos e, consequentemente o soro de leite, permitindo a seleção das indústrias de interesse.

A partir da identificação dos participantes, os produtores de soro de leite, foi aplicado um questionário semiestruturado, composto de 26 questões, sendo possível obter informações referentes a percepção de estímulos intangíveis no momento da entrevista.
Foi conduzido um estudo de caráter transversal, individuado e observacional, pois a coleta dos dados ocorreu em um único momento no tempo.

Foram identificados e analisados nove laticínios produtores de queijos. A duração das entrevistas variou entre 10 a 20 minutos, sendo as respostas registradas em questionários impressos. Posteriormente os dados foram tabulados no software Excel (2010).

Os dados foram organizados através de tabelas e do gráfico de colunas. Foram computadas as frequências absolutas relativas e percentuais.

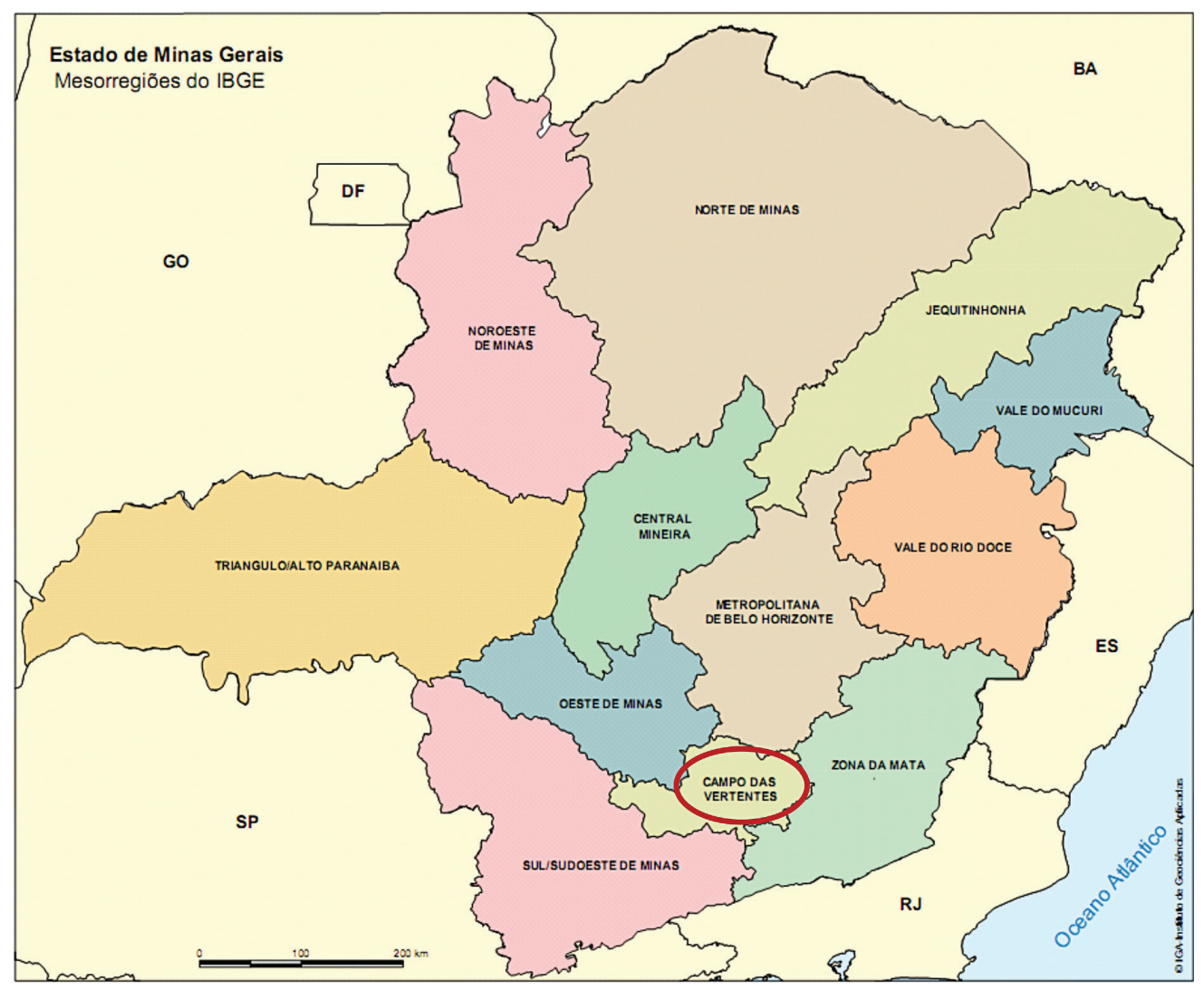

FONTE: Adaptado de Silva Junior et al. (2011).

Figura 1 - Mapa de Minas Gerais com aregião do Campo das Vertentes em destaque 
Em seguida, o teste para proporção ao nível nominal de 5\% de significância foi utilizado para garantira confiabilidade das respostas (BUSSAB; MORETIN, 2013).

\section{RESULTADOS E DISCUSSÃO}

A Figura 2 apresenta os tipos de queijos produzidos na mesorregião do Campo das Vertentes. Deve-se ressaltar que após o processo de fabricação de queijos, pode-se resultar em dois tipos diferentes de soro de leite: o doce ou o ácido, o que implica em tecnologias diferentes de utilização para estes subprodutos.

Observa-se, na Figura 2, que existe uma grande variedade de queijos que são produzidos na mesorregião do Campo das Vertentes, MG, e que cada laticínio produz mais de uma variedade de queijo, com predominância na fabricação de queijos que geram soro doce.

Os queijos fabricados pelos laticínios analisados são: minas frescal, minas padrão, muçarela, prato e ricota que são fabricados por cinco laticínios; o queijo gouda, por três laticínios; minas frescal light, reino e parmesão por dois laticínios; e os queijos minas frescal free lactose, minas padrão light, lanche, lanche free lactose, prato free lactose, bola, cobocó, cottage, provolone, gorgonzola, estepe, tilsit e gruyére, apenas por um laticínio.

Como se vê na Figura 2, a maioria queijos produzidos na região geram soro doce, com exceção do cottage e da ricota. Entretanto, quando o volume de produção e a tecnologia empregada são levados em consideração, o resultado é uma produção equivalente de soro ácido e doce. Em termos absolutos, os laticínios analisados produzem um total de 64.886 litros de soro doce e 61.744 litros de soro ácido, perfazendo um total de 126.630 litros de soro de leite por dia.

Dos nove participantes da pesquisa, quando questionados sobre algum tipo de beneficiamento do soro de leite, dois $(22 \%)$ relataram que faziam o resfriamento do produto, e um desses possuía membrana de concentração de soro. Os demais participantes não possuem este equipamento e não fazem nenhum tipo de beneficiamento.

Conforme Almeida et al. (2001), a limitação da utilização do soro se deve a alta carga orgânica, o que impossibilita o arma-

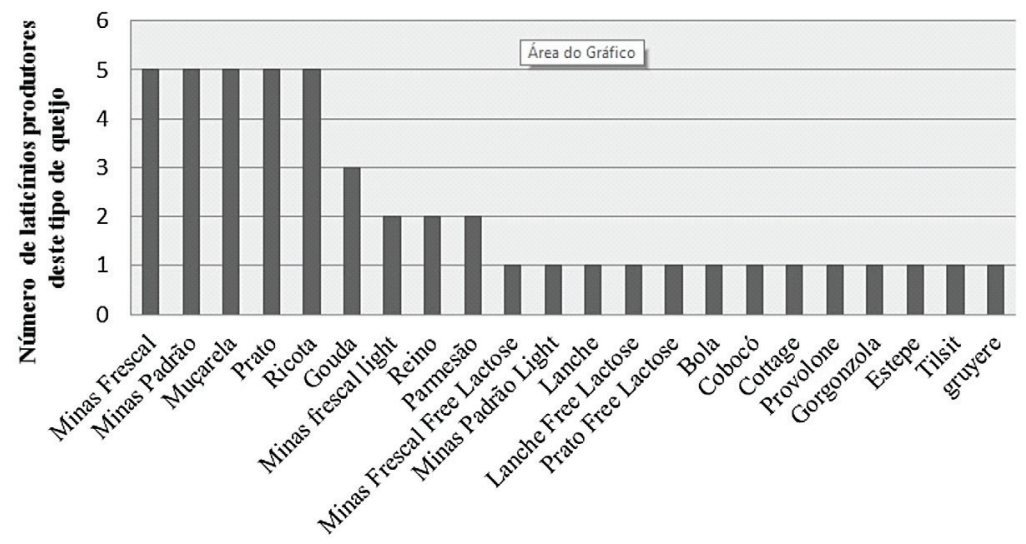

Figura 2 - Tipos de queijos fabricados na região Campo das Vertentes 
zenamento prolongado devido ao rápido processo de fermentação e/ou deterioração que pode ocorrer. Isso pode ser contornado pela utilização rápida deste material ou aplicação de medidas de conservação, como a refrigeração.

A Figura 3 representa a quantidade de queijo produzida diariamente pelos laticínios. A análise do volume de queijo processado diariamente mostrou que $88,9 \%$ dos laticínios produzem até $10.000 \mathrm{~kg}$ de queijo por dia. Não há laticínios produzindo na faixa entre $10.000 \mathrm{~kg} /$ dia a $50.000 \mathrm{~kg} / \mathrm{dia}$. $11,1 \%$ dos laticínios produzem entre 50.000 a $60.000 \mathrm{~kg} / \mathrm{dia}$.
Nota-se também que $88,9 \%$ dos laticínios são de pequeno e médio porte e processam entre 0 a $10.000 \mathrm{~kg}$ de queijo por dia.

Sobre o destino do soro de leite doce, os resultados estão apresentados nas Figuras 4 e 5 . No que tange o destino do soro de leite doce, na Figura 4 verifica-se que a maior parte $(33 \%)$ se destina à alimentação animal. Do restante, $25 \%$ dos laticínios não produzem este tipo de soro de leite, $17 \%$ fazem doações, $17 \%$ comercializam e $8 \%$ utilizam no próprio laticínio.

Observou-se que o receptor do soro de leite doado utiliza este soro para alimentação animal e o soro de leite utilizado no

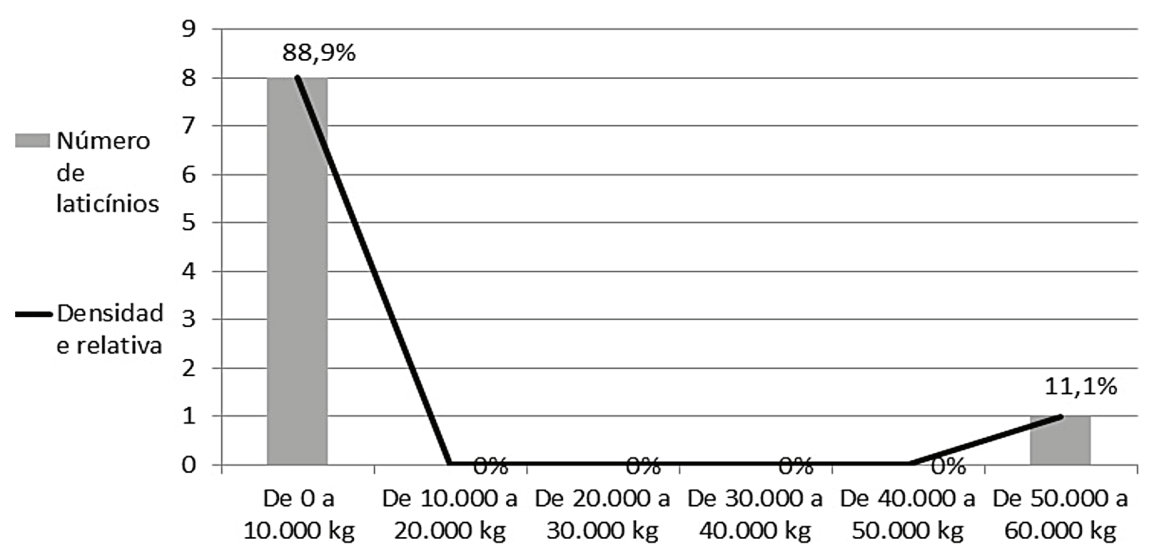

Figura 3 - Produção diária de queijo. Densidade relativa: quantidade de observações; $\sum \%$ : percentual acumulado

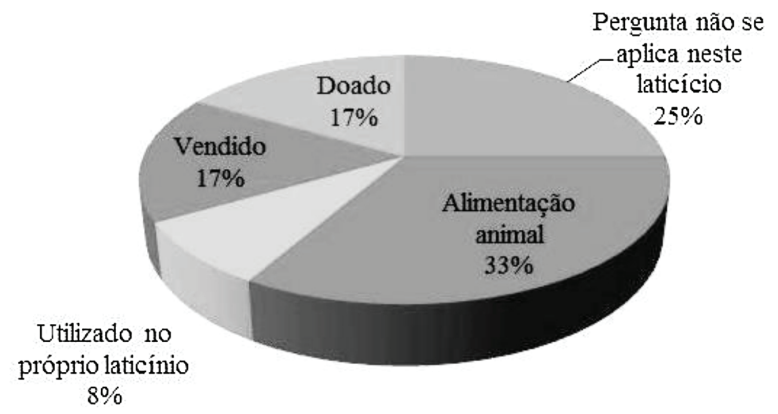

Figura 4 - Destino do soro de leite doce produzido pelos laticínios 
próprio no laticínio foi destinado para a fabricação de ricota.

Observa-se na Figura 5, que 40\% do soro de leite ácido são destinados à alimentação animal, 30\% dos laticínios não produzem este tipo de soro, $20 \%$ são doados e $10 \%$ utilizam no próprio laticínio.

A Tabela 1 apresenta o destino do soro doce e ácido de acordo com o volume de queijo processado diariamente. Verifica-se que os laticínios que processam até $1000 \mathrm{~kg}$ por dia destinam o soro doce para doação e alimentação animal. O mesmo destino pode ser observado para o soro ácido.

Já os laticínios que processam de $1000 \mathrm{~kg}$ a $5000 \mathrm{~kg}$ diários utilizam parte do soro doce no próprio laticínio e outra parte para alimentação animal e o soro ácido para alimentação animal, conforme pode ser observado na Tabela 1 .

Aqueles que processam entre $5000 \mathrm{~kg}$ a $10000 \mathrm{~kg}$ por dia destinam o soro doce para a venda e alimentação animal. Nesta faixa de volume, não há produção de soro ácido. Já os que processam de $50000 \mathrm{~kg}$ a $60000 \mathrm{~kg}$ diários também vendem o soro doce e utilizam o soro ácido para alimentação animal.

Estes resultados estão de acordo com Fontes et al. (2006) que verificaram que o soro de leite resultante do processamento do queijo pode ser utilizado na criação de machos leiteiros, como forma de reduzir custos de criação e de utilização de resíduos potencialmente poluentes.

A venda do soro de leite para as indústrias que possuem equipamentos de con-

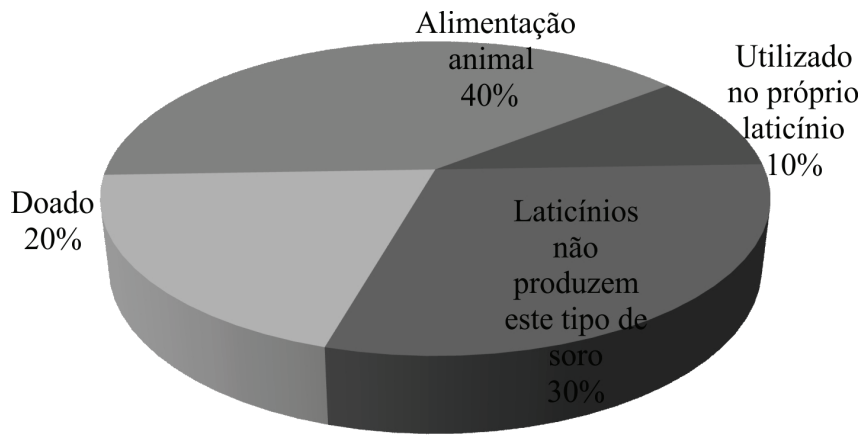

Figura 5 - Destino do soro de leite ácido produzido pelos laticínios

Tabela 1 - Produção diária de queijo e a destinação do soro de leite doce e ácido

\begin{tabular}{cccc}
\hline $\begin{array}{c}\text { Produção diária } \\
\text { de queijo }\end{array}$ & $\begin{array}{c}\text { Número de } \\
\text { laticínios }\end{array}$ & $\begin{array}{c}\text { Destino do soro } \\
\text { de leite doce }\end{array}$ & $\begin{array}{c}\text { Destino do soro } \\
\text { de leite ácido }\end{array}$ \\
\hline Até $1.000 \mathrm{~kg}$ & 2 & $\begin{array}{c}\text { Doação e } \\
\text { alimentação animal } \\
\text { Próprio laticínio e } \\
\text { alimentação animal }\end{array}$ & $\begin{array}{c}\text { Doação e } \\
\text { alimentação animal } \\
\text { Alimentação animal }\end{array}$ \\
$5.000 \mathrm{~kg}$ a $5.000 \mathrm{~kg}$ & 5 & $\begin{array}{c}\text { Venda e } \\
\text { alimentação animal } \\
\text { Venda }\end{array}$ & Não há produção \\
$50.000 \mathrm{~kg} \mathrm{a} 60.000 \mathrm{~kg}$ & 1 & 1 & Alimentação animal \\
\hline
\end{tabular}


centração e/ou secagem é uma alternativa que gera receita para o escoamento do produto. $\mathrm{O}$ aproveitamento do soro em produtos de alto valor agregado requer investimentos razoavelmente elevados e que demandam volumes expressivos de soro para justificar tais investimentos.

Grande parte do soro de leite gerado no Brasil e no estado de Minas Gerais tem origem nas operações de pequenas e médias queijarias, nas quais se torna difícil o investimento em tecnologia necessária para o beneficiamento deste subproduto.

Desta forma, observou-se que o volume processado está ligado ao tipo de destinação do soro de leite. Os laticínios com um baixo volume de produção doam ou utilizam o produto para alimentação animal; já os que produzem acima de 1000 litros diários, além da doação e alimentação animal, aproveitam o produto no próprio laticínio para a fabricação de outros produtos lácteos ou vendem para indústrias de processamento de soro. Alves et al. (2014) verificaram que a tendência é a instalação de unidades centrais de processamento que recebam o soro produzido pelas queijarias de uma determinada região.

Os resultados apresentados na Tabela 2, mostram que os laticínios com até 5 anos de atividade representam $11,1 \%$ e utilizam o soro doce no próprio laticínio e para alimentação animal e o soro ácido somente para alimentação animal.

Os laticínios entre 5 a 10 anos representam $22,2 \%$ e fazem doação do soro doce e ácido. Dos laticínios com 10 a 15 anos de atividade, $11,1 \%$ vendem o soro doce e destinam para alimentação animal o soro ácido.

As empresas entre 15 a 20 anos, 11,1\%, utilizam o soro doce para alimentação animal e não há produção de soro ácido. Em $33,4 \%$ daquelas entre 25 a 30 anos o soro doce é doado ou utilizado na alimentação animal, sendo o soro ácido doado, utilizado na alimentação animal e no próprio laticínio.

Nos laticínios entre 45 a 50 anos de atividade ( $11,1 \%$ do total), o soro doce é vendido e utilizado na alimentação animal e não há produção de soro ácido.

Pode-se observar que, independente do início da atividade do laticínio, no que

Tabela 2 - Média de idadedos laticínios e a destinação do soro de leite

\begin{tabular}{|c|c|c|c|c|}
\hline $\begin{array}{l}\text { Idade do } \\
\text { laticínio }\end{array}$ & $\mathrm{N}$ & $\%$ & $\begin{array}{l}\text { Destino do soro } \\
\text { de leite doce }\end{array}$ & $\begin{array}{l}\text { Destino do soro } \\
\text { de leite ácido }\end{array}$ \\
\hline De 0 a 5 anos & 1 & 11,1 & $\begin{array}{l}\text { Próprio laticínio e } \\
\text { alimentação animal }\end{array}$ & Alimentação animal \\
\hline De 5 a 10 anos & 2 & 22,2 & Doação & Doação \\
\hline De 10 a 15 anos & 1 & 11,1 & Venda & Alimentação animal \\
\hline De 15 a 20 anos & 1 & 11,1 & Alimentação animal & Não há produção \\
\hline De 25 a 30 anos & 3 & 33,4 & $\begin{array}{c}\text { Doação } \\
\text { e } \\
\text { alimentação animal }\end{array}$ & $\begin{array}{c}\text { Doação, } \\
\text { alimentação animal } \\
\text { e próprio laticínio }\end{array}$ \\
\hline De 45 a 50 anos & 1 & 11,1 & $\begin{array}{c}\text { Venda e } \\
\text { alimentação animal }\end{array}$ & Não há produção \\
\hline Total & 9 & 100,0 & & \\
\hline
\end{tabular}

$\mathrm{N}$ : quantidade de observações; $\sum \%$ : percentual acumulado. 
se refere a destinação do soro de leite, há predominância para a alimentação animal e doação. Destaca-se que, nos laticínios mais novos no mercado, a doação do soro lácteo e a utilização para a alimentação animal prevalecem entre as alternativas. Este subproduto poderia tornar-se uma opção de aproveitamento pelas indústrias, na forma de produtos com valor agregado.

De acordo com Santos; Ferreira (2001), a procura do consumidor brasileiro por produtos mais saudáveis, inovadores, seguros e de utilização prática tem contribuído para o crescimento da produção das bebidas lácteas. Logo, uma alternativa para a utilização do soro de leite seria para a produção de bebida láctea.

No Brasil esta alternativa tem-se tornado uma das principais opções de aproveitamento do soro de leite, pois apresenta baixo custo, facilidade de processamento, além de ser possível o uso dos equipamentos já existentes na indústria (PINTADO et al., 2001).

O soro, além de seu alto valor nutritivo, substitui a custos mais competitivos, o leite em pó em vários alimentos industrializados como os infantis, margarinas, bolachas, biscoitos, conservas e embutidos, bebidas lácteas, na indústria farmacêutica, cosmética, etc.

\section{Dificuldades na utilização e comerciali- zação do soro de leite}

No intuito de refinar a pesquisa, quando os produtores de queijos foram questionados sobre as dificuldades encontradas na utilização do soro de leite no próprio laticínio, diversas informações foram registradas tais como: o soro de leite produzido era contaminado, necessitando de um processo de beneficiamento, o que encareceria o produto. Outro participante relatou sobre a falta de equipamentos e de compradores para os produtos produzidos a partir do soro de leite. Outra informação foi que dos laticínios que reutilizam o soro de leite, o reaproveitamento era destinado para a produção de ricota.

As dificuldades encontradas para a venda do soro de leite foram em relação ao transporte até o comprador; à falta de estrutura do próprio laticínio; o custo de resfriamento e à falta de interesse em comercializar o produto.

Conforme observado por Rohlfes et al. (2015), o aproveitamento dos subprodutos da indústria de laticínios, em especial do soro de leite, apresenta como principal dificuldade o fato do soro ainda ser visto como resíduo e não como matéria-prima.

Dessa forma, não há uma preocupação em se buscar uma maior conservação e estabilidade do soro de leite, com utilização de baixas temperaturas ou concentração para garantir sua qualidade.

Nos laticínios que vendem o soro de leite, o valor médio pago foi entre $\mathrm{R} \$ 0,06 \mathrm{e}$ $\mathrm{R} \$ 0,07$ para o produto líquido e $\mathrm{R} \$ 1,00 / \mathrm{kg}$ por sólidos totais para o soro concentrado.

Resultados semelhantes foram obtidos por Chehadi (2004) que verificou que nas indústrias este produto contém valor comercial baixo quando in natura e apresenta alto custo de captação. As empresas que vendem o produto relataram que $0,01 \%$ de seu faturamento advêm da venda do soro de leite.

Observou-se nos laticínios que a venda do soro de leite líquido e concentrado é realizada para quatro grandes empresas. $\mathrm{O}$ transporte do produto vendido é realizado por terceiros até o comprador.

O questionário contemplou também sobre o conhecimento dos gestores em relação ao valor monetário dos constituintes do soro de leite. Conforme Tabela 3, 77,8\% dos participantes possuem conhecimento sobre o valor (monetário) dos constituintes do soro de leite.

Todos os participantes relataram ter conhecimento e estão cientes sobre o impacto 
ambiental do descarte inadequado do soro de leite no meio ambiente.

Em relação à qualificação, foi questionado se os gestores já participaram de algum curso, palestra ou minicurso sobre o soro de leite. Como pode ser observado na Tabela 4, 44,4\% dos laticínios possuem gestores que buscaram algum tipo de qualificação sobre o soro de leite e em 55,6\% dos laticínios, os gestores nunca participaram de cursos para ampliar os seus conhecimentos sobre o soro de leite.

Uma fatia considerável dos produtores de queijo possui conhecimento sobre os valores do soro de leite e têm consciência da questão ambiental. Quase a metade têm conhecimento técnico para a utilização do produto no próprio laticínio. Porém, estas informações não os influenciam totalmente na tomada de decisão afim de alterar o perfil da utilização do soro do leite, voltado para uma maior produção de produtos com valor agregado, o que poderia gerar uma renda extra não existente, na realidade atual.

\section{CONCLUSÕES}

Os resultados experimentais permitem concluir que a região do Campo das Vertentes é formada, em sua maioria, por laticínios de pequeno e médio porte e que processam um volume total diário de 243.500 litros de leite, sendo que aproximadamente 195.000 litros destinados à produção de queijo, o que gera um volume total de soro, doce e ácido, de 126.630 litros.

O destino mais comum do soro de leite é para a alimentação animal e doação, o que representa um grande potencial de mercado para o processamento do produto in natura $\mathrm{e}$ produtos derivados do soro de leite.

Embora os laticínios estejam próximos a indústrias processadoras, num raio máximo de $300 \mathrm{~km}$ de distância, estas não possuem interesse ou falta estrutura para aproveitar ou comercializar o produto.

Tabela 3 - Conhecimento dos gestores sobre o valor monetário dos constituintes do soro de leite

\begin{tabular}{cccc}
\hline $\begin{array}{c}\text { Conhecimento sobre o valor monetário } \\
\text { dos constituintes do soro de leite }\end{array}$ & $\mathrm{N}$ & $\%$ & $\sum \%$ \\
\hline Sim & 7 & 77,8 & 77,8 \\
Não & 2 & 22,2 & 100,0 \\
Total & 9 & 100,0 & \\
\hline
\end{tabular}

$\mathrm{N}$ : quantidade de observações; $\sum \%$ : percentual acumulado.

Tabela 4 - Empresas (laticínios) em que os gestores participaram de cursos, palestras e/ou minicursos sobre o soro de leite

\begin{tabular}{cccc}
\hline Gestores que participaram de cursos & N & $\%$ & $\sum \%$ \\
\hline Sim & 7 & 77,8 & 77,8 \\
Não & 2 & 22,2 & 100,0 \\
Total & 9 & 100,0 & \\
\hline
\end{tabular}

N: quantidade de observações; $\sum \%$ : percentual acumulado. 


\section{REFERÊNCIAS}

ALICEWEB. Importações de soro de leite, modificado ou não, mesmo concentrado, adoc. 2015. Disponível em: <http://aliceweb. mdic.gov.br//consulta-ncm/consultar $>$. Acesso em: 13 jan. 2015.

ALMEIDA, K. E. de; BONASSI, I. A.; ROÇA, R. de O. Características físicas e químicas de bebidas lácteas fermentadas e preparadas com soro de queijo Minas Frescal. Ciência e Tecnologia de Alimentos, v. 21, n. 2, p. 187-192, 2001.

ALVES, M. P. et al. Soro de leite e sua processabilidade: processability of whey. In: SIMPÓSIO NACIONAL DE BOVINOCULTURA DE LEITE, 4., INTERNATIONAL SYMPOSIUM OF DAIRY CATTLE, 2., 2013, Viçosa. Anais eletrônicos... Viçosa: UFV, 2013. p. 257-278. Disponível em: $<$ http://www.simleite.com/home/anais/IV/16. pdf $>$. Acesso em: 25 ago. 2015.

ASSOCIAÇÃO BRASILEIRA DAS INDÚSTRIAS DE QUEIJO (ABIQ) 2014. Destaques. Disponível em: http://www.abiq. com.br. Acesso em: 10 mar. 2014.

BIEGER, A.; RINALDI, R. N. Reflexos do reaproveitamento de soro de leite na cadeia produtiva de leite do oeste do Paraná. In: CONGRESSO DA SOCIEDADE BRASILEIRA DE ECONOMIA, ADMINISTRAÇÃO E SOCIOLOGIA RURAL, 47, 2009, Porto Alegre. Anais... Porto Alegre: UFRGS, 2009. 1 CD-ROM.

CHEHADI, M. C. G.; VIEIRA, J. A. G. Comportamento reológico do soro de queijo. Revista do Instituto de Laticínios Cândido Tostes, v. 59, n. 339, p. 169-172, 2004.

FONTES, F. A. P. V. et al. Desempenho de bezerros alimentados com dietas líquidas à base de leite integral ou soro de leite. Arquivo Brasileiro de Medicina Veterinária e Zootecnia, v. 58, p. 212-219, 2006.

MAGAlHÃES, K. T. et al. Comparative study of the biochemical changes and volatile compound formations during the production of novel whey-based kefir beverages and traditional milk kefir. Food Chemistry, v. 126, n. 1, p. 249-253, 2011.

MINISTÉRIO DA AGRICULTURA, PECUÁRIA E ABASTECIMENTO. Relação de estabelecimentos. Disponível em: $<$ http:// www.agricultura.gov.br/portal/page/portal/ Internet-MAPA/pagina-inicial/servicos-esistemas/sistemas/sif $>$. Acesso em: 13 ago. 2015.

MIZUBUTI, Ivone Yurika. Soro de leite: composição, processamento e utilização na alimentação. Semina: Ciências Agrárias, v. 15, n. 1, p. 80-94, 1994.

PINTADO, M. E. et al. Review: Technology, Chemistry and Microbiology of Whey Cheeses. Food Science And Technology International, [s.1.], v. 7, n. 2, p. 105-116, 2001.

RECH, R. Estudo da produção de betagalactosidase por leveduras a partir do soro de queijo. 2003. 86 f. Tese (Doutorado) - Curso de Centro de Biotecnologia do Estado do Rio Grande do Sul, Universidade Federal do Rio Grande do Sul, Porto Alegre, 2003.

RÉVILLION, J. P. P. et al. Produção de extratos de leveduras de uso alimentar a partir de soro de queijo: abordagem de elemenmentos técnicos e mercadológicos relevantes. Ciência e Tecnologia de Alimentos, v. 20, n. 2, p. 246-249, 2000. 
ROHLFES, A. L. B. et al. Indústrias Lácteas: Alternativas de aproveitamento do soro de leite como forma de gestão ambiental. Tecnológica: Revista do depto. de Química e Física, do depto de Engenharia, Arquitetura e Ciências Agrárias e do Mestrado em Tecnologia Ambiental, v. 15, n. 2, p. 7983, 2015. Disponível em: <https://online. unisc.br/seer/index.php/tecnologica/article/ view/2350>. Acesso em: 20 out. 2015.

SANTOS, J. P. V.; FERREIRA, C. L. de L. F. Alternativas para o aproveitamento de soro de queijo nos pequenos e médios laticínios. Revista do Instituto de Laticínios Cândido Tostes, v. 56, n. 3, p. 44-50, 2001.

SILVA JUNIOR, F. A. et al. Fatores de risco associados à infecção por Cryptosporidium spp. e Giardiaduodenalis em bovinos leiteiros na fase de cria e recria na mesorregião do Campo das Vertentes de Minas Gerais. Pesquisa Veterinária Brasileira, v. 31, n. 8, p. 690-696, 2011.

SMITH, L. L. Overtraining, excessive exercise, and altered immunity: is this a T helper-1 versus $\mathrm{T}$ helper-2 lymphocyte response? Sports Medicine, v. 33, n. 5, p. 347-364, 2003.

WIKIPÉDIA. Mesorregião do Campo das Vertentes. Disponível em: <https://pt. wikipedia.org/wiki/Mesorregião_do_Campo das_Vertentes>. Acesso em: 23 fev. 2015. 